\title{
New Technique for Enhancing Helium Production in Ferritic Materials
}

CONF-871036--23

DE88 003048

\author{
L. R. Greenwood and D. G. Graczyka \\ Chemical Technology Division \\ analytica! Chemistry Laboratory \\ Argonne National Laboratory \\ Argonne, IL 60439 USA \\ D. W. Kneff \\ Rockwell Isternational Corporation \\ Canoga Park, CA 91303 USA
}

\section{Proceedings of Third International Conference on Fusion Reactor Materials October 4-8, 1987, Karlsruhe, F. R. Germany}

\author{
DISCLAIMER
}

\begin{abstract}
This repori was prepared as an account of work sponsored by an agency of the United States Government. Neither the United States Government nor any agency theieof, nor any of their employees, makes at:y warranty, express or implied, or assumes any legal liability or responsibility for the accuracy, completeness, or usefulness of any information, apparatus, product, or process disclosed, or represents that its use would not infringe privately owned rights. Reference herein to any specific commercial product, process, or service by trade name. trademark, manufacturer, or otherwise does not necessarily constitute or imply its endorsement, recommendation, or favoring by the United States Government or any agency thereof. The views and opinions of authors expressed herein do not necessarily state or reflect those of the United States Government or any agency thereof.
\end{abstract}

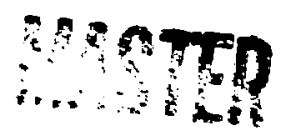


New Tech rique for Enhancing Helium Production in Ferritic Materials

L. R. Greenwood and D. G. Graczyk, Argonne National Laboratory, Argonne, IL USA D. W. Kneff, Rockwell International Corporation, Canoga Park, CA USA

\section{Abstract}

Analyses of iron samples irradiated up to $10^{27} \mathrm{n} / \mathrm{m}^{2}$ in HFIR found more helium than was expected from fast neutron reactions at high neutron fluences. The helium excess increases systematically with neutron exposure, suggesting a transmutationdriven process. The extra helium may be produced in two different ways, either by fast neutron reactions on the transmuted isotopes of iron or by a thermal neutron reaction with the radioactive isotope ${ }^{55} \mathrm{Fe}$. Radiometric and mass spectrometric measurements of the iron isotopes composing the irradiated samples have been used to determine limits on the cross sections for each process. Either of these processes can be used to enhance helium production in ferritic materials during irradiations in mixed-spectrum reactors by isotopically enriching the samples. Further work is needed to clarify the reaction mechanisms and helium production cross sections. Our measurements determined the thermal neutron total absorption cross section of ${ }^{56} \mathrm{Fe}$ to be $13.2 \pm 2.1$ barns.

\section{Introduction}

Helium production cross sections are needed to predict helium levels accurately in irradiated fusion materials. We have been engaged in a long-standing collaboration to measure such helium production. Joint experiments have been conducted at a variety of neutron irradiation facilities including fission reactors, ${ }^{1} 14 \mathrm{MeV}$ sources, ${ }^{2}$ and higher-energy accelerator-based neutron sources. ${ }^{3}$ The experimental analysis combines radiometric dosimetry at Argonne with helium mass spectrometry at Rockwell to determine the helium generation cross sections. Data published recently ${ }^{1}$ for the High Flux Isotope Reactor (HFIR) at Oak Ridge National Laboratory are used here to examine helium production reactions for the iron isotopes. The enhanced helium production which we observed in iron at high neutron fluences could be applied to fusion materials testing by using isotopically enriched materials. In particular, a thermal neutron effect could be used to generate fusion-like helium-to-displacement damage ratios in mixed-spectrum fission reactor irradiations of iron-based materials.

\section{Experimental Method and Results}

High-purity (99.99\%) iron samples were irradiated at three locations in three separate fusion materials experiments in the Peripheral Target Position of HFIR. These iron samples were used tor both activation and helium measurements. Other radiometric dosimeters were also included and the activation measurements were used to determine the neutron energy spectra using spectral adjustment procedures."

The helium measurements were performed by isotope-dilution gas mass spectrometry of vaporized samples under vacuum by adding a known spike of ${ }^{3} \mathrm{He}$, as described previously ${ }^{5}$. The nine iron wires were about 0.030 inches in diameter by 0.125 inches in

This work was supported by the U.S. Department of Energy, office of Fusion Energy, under contract no. W-38-109-Eng-38. 
length. Each sample was acid-etched prior to analysis, to remove any possible helium recoil effects into or out of the surface layer, and segmented for multiple analyses.

The neutron fluences and measured helium levels are listed in columns 1 and 2 of Table I. Helium production from fast neutrons can be readily calculated from the adjusted neutron energy spectra using the evaluated helium cross sections given in the ENDF/B-V Gas Production File ${ }^{6}$ (column 3 of Table I). It is evident from a comparison of the measured and calculated helium that there is a sysiematic trend with increased neutron exposure, as shown in Table 1 (column 4) and figure 1 (circles).

\section{Measurements and Calculations of Iron Isotope Ratios}

The rate of helium production from fast neutrons will change during the course of irradiation due to transmutation of the iron isotopes. We have used two techniques to measure the various iron isotopes in the irradiated samples. Thermal ionization mass spectrometry was performed on three samples to measure the ratios of all iron isotopes, and the results are given in Tables 11 and III. ${ }^{55} \mathrm{Fe}$ was also measured by liquid scintillation spectrometry ${ }^{7}$ and those results are given in Table III. Both types of analyses were performed using dissolutions of the same three samples, and chemical separations were performed to remove the possibility of interferences. ${ }^{8}$ Since ${ }^{55}$ Fe decays to ${ }^{55} \mathrm{Mn}$ and $\mathrm{Mn}$ is more volatile than $\mathrm{Fe}$ in the thermal ionization mass spectrometry technique, Fe-Mn separations were performed within a day of the measurements. All data in Tables II and III have been corrected for decay of ${ }^{55} \mathrm{Fe}$ since irradiation.

A computer program was developed to calculate the isotopic ratios and helium production it each sample. These calculations consider all contributing and competing reaction channels including thermal $(n, \gamma)$, total absorption, and $(n, \alpha)$ for ${ }^{55} \mathrm{Fe}$. Thermal neutron cross sections were adopted from ENDF/B-V. ${ }^{9}$ An epithermal neutron correction of about $7 \%$ was also made based on previous measurements of the neutron energy spectrum in HFIR. ${ }^{4}$ In all subsequent discussions, references to thermal cross sections will be understood to include this effect. The amount of ${ }^{55} \mathrm{Fe}$ in each sample depends on the production from ${ }^{54} \mathrm{Fe}$, and losses by radioactive decay, and the burnup of ${ }^{55} \mathrm{Fe}$. The neutron fluence levels were taken from our radiometric dosimetry data, which included measurements of the ${ }^{54} \mathrm{Fe}(\mathrm{n}, \mathrm{p})^{54} \mathrm{Mn}$ and ${ }^{58} \mathrm{Fe}(\mathrm{n}, \gamma)^{50} \mathrm{Fe}$ reactions for each sample. As shown in Table II, the ${ }^{54} \mathrm{Fe}$ atomic fractions are very well-fit by the data $(\mathrm{O} / \mathrm{E}=0.999 \pm 0.004)$, thus confirming our calculation of the production of ${ }^{55} \mathrm{Fe}$. The total thermal burnup cross section of ${ }^{55} \mathrm{Fe}$ can thus be uniquely determined since the decay rate is also well-known $(2.73 \pm 0.03$ years $) .{ }^{10}$ A total absorption cross section for ${ }^{55} \mathrm{Fe}$ of $13.2 \pm 2.1$ barns provides an excellent fit to the ${ }^{55} \mathrm{Fe}$ data $(\mathrm{C} / \mathrm{E}=$ 1.00 10.03 ), as shown in Table III. The only previous estimate of this cross section gave a value less than 170 barns. ${ }^{11}$

Our calculations for the higher-mass isotopes of iron are also given in Table II. As can be seen, the agreement is quite good for ${ }^{56} \mathrm{Fe}$ and ${ }^{57} \mathrm{Fe}(\mathrm{C} / \mathrm{E}=0.996$ and 1.003 , respectively); however, the calculations overpredict the amount of ${ }^{58} \mathrm{Fe}(\mathrm{C} / \mathrm{E}=$ 1.23). The thermal cross sections and resonance integrals from ENDF/B-V are noted to have uncertainties of about $5 \%$ for ${ }^{54,56,58} \mathrm{Fe}$ and $12 \%$ for ${ }^{57} \mathrm{Fe}$. In order to fit our 
iron isotopic data for ${ }^{58} \mathrm{Fe}$, it is necessary to lower the thermal neutron capture cross section for ${ }^{87} \mathrm{Fe}$ by about $20 \%$. The calculations are rather insensitive to the other cross sections. Since ${ }^{58} \mathrm{Fe}$ is produced faster than it is consumed, the fit is slightly improved by reducing the ${ }^{56} \mathrm{Fe}$ cross section; however, the fit only weakly depends on the ${ }^{58} \mathrm{Fe}$ cross section. Consequently, the thermal neutron cross section for ${ }^{57} \mathrm{Fe}$ should be lowered from $2.48 \pm 0.30$ barns (ENDF/B-V) ${ }^{9}$ to about 2.0 barns.

\section{Calculation of Helium Production}

As described above calculations of helium production from fest neutrous using ENDF/B-V underpredicted the helium at high fluences. A more detailed calculation was then performed using the above transmutation rates. Unfortunately, the energydependent helium cross section for each isotope is not well-known. Cross sections were thus calculated for each iron isotope using the THRESH2 computer code, ${ }^{12}$ and the results are shown in figure 2 . Although this code is based only on a semi-empirical fit to the partition of the total reaction cross sections, the abundance-weighted results for iron appear to be in reasonable agreement with the cross section in the ENDF/B$V$ Gas Production File. We also note that the iron isotopic helium cross sections are in reasonable agreement with our published results at $14 \mathrm{MeV}_{0}^{2}$ We averaged the THRESH2 cross sections over the HFIR neutron spectra to obtain values of 0.145 $\mathrm{mb}, 0.429 \mathrm{mb}, 0.061 \mathrm{mb}, 0.199 \mathrm{mb}$, and $0.012 \mathrm{mb}$ for ${ }^{54,55,56,57,58} \mathrm{Fe}$, respectively. The abundance-weighted spectral average for natural iron is $0.069 \mathrm{mb}$, compared to $0.070 \mathrm{mb}$ from ENDF/B-V. Helium calculations using THRESH2 cross sections and calculated transmutation rates of the iron isotopes are also given in Table I (column 5) and shown in figure 1 (triangles).

Although the isotopic helium calculations improve the fit to the data, there is still a clear trend with neutron exposure, as shown in figure 1 and Table I (column 6). Such a trend is similar to the situation with nickel ${ }^{13}$ and copper, ${ }^{14}$ where thermal neutrons produce significant helium from transmutants. Consequently, we investigated the thermal, two-step reaction ${ }^{54} \mathrm{Fe}(\mathrm{n}, \gamma)^{55} \mathrm{Fe}(\mathrm{n}, \alpha)$. It is very unlikely that thermal neutron helium production could be significant for any other isotope in our amples. All of the other iron isotopes have very well-known thermal neutron properties except for ${ }^{59} \mathrm{Fe}$, whose short halflife (45 days) would cause the helium to saturate at high fluences. The only other long-lived isotopes which were produced either have very wellknown nuclear properties or are only weakly formed from : wst neutron reactions at rates which would be too low to explain our excess helium. Thermal helium production is enegertically allowed from ${ }^{55} \mathrm{Fe}$, whose $\mathrm{Q}$-value of $+3.58 \mathrm{MeV}$ is much larger than the other iron isotopes. We have also looked at impurities in the jron which might produce helium; however, the only known candidate, boron, is far too low (0.2 appb) in these samples.

As seen in Table $I$, at the lowest neutron fluences the calculations exceed the measurements. Hence, in order to examine any possible thermal effects, we first readjusted the fast neutron helium cross sections. Based on the data, the calculated fast helium should be reduced by a factor of at least 0.94 (ENDF) or 0.90 (THRESH) simply to fit 
the measurements at the lowest fluences. Data from iron measurements in other mixedspectrum reactors at lower fluences give a $\mathrm{C} / \mathrm{E}$ ratio of $0.92-1.01^{15}$ and measurements in fast reactors give a value of about $0.84 .{ }^{16}$ These differences are compatible with the estimated uncertainties of about $10 \%$ in the neutron spectral analyses; however, spectral differences between facilities may also be significant. In the present work, we have assumed that the fast helium production in HFIR must be reduced by a factor between $0.84-0.88$.

\section{Comparison of Calculations with Helium Measurements}

The data in Table I clearly indicate that the helium levels exceed the fast helium production from natural iron using the ENDF/B-V Gas Production File. If we instead use the isotopic values in THRESH2 for the transmuted iron isotopes, the fit is clearly improved and the difference or excess helium is cut about in half. We are thus faced with three possibilities. Firstly, the THRESH2 helium values with $\mathrm{C} / \mathrm{E}$ of 1.08 (Table I, column 6) could be improved to $1.00 \pm 0.0 \mathrm{~A}$ if we reduce the fast helium cross sections by 0.92 . It is further possible that by varying the isotopic fast $(n, a)$ cross sections we could fit the data more precisely; however, we have not attempted to do this. In this case, there would be no effect from thermal neutrons. Secondly, the THRESH2 values may be entirely misleading and thus should be ignored. In this case, we should use the ENDF values for natural iron and the entire helium excess is due to a thermal neutron effect from ${ }^{55} \mathrm{Fe}$. Finally, it is possible that the THRESH2 values are about right, in which case about half the excess is due to fast transmutation and half in due to thermal neutron effects from ${ }^{55} \mathrm{Fe}$.

If we assume that the excess in the helium calculations is indeed due to thermal helium production from ${ }^{55} \mathrm{Fe}$, then we can use the previously described computer code to determine the cross section. Unfortunately, we do not know exactly hiw to adjust the fast helium calculations. If we use the ENDF fast helium values, reducied by a factor of 0.84-0.88, and assume that the entire helium excess is d:se to thermal production from ${ }^{55} \mathrm{Fe}$, then the cross section is $18 \pm 3$ millibarns. If we instead use the THRESH2 helium production, similarly reduced, then we deduce that the thermal helium production cross section is $\mathbf{9} \pm \mathbf{4}$ millibarns. The uncertainties are determined from the uncertainties in the helium measurements ( $1 \%)$, neutron fluences ( $5 \%)$, and a sensitivity analysis of the uncertainties in the other parameters. Both cases are illustrated in figure 3.

\section{Implications for Fusion Materials Testing}

Simulations of fusion reactor damage and gas production in fission reactor irradiations are not generally possible since the low helium rates do not produce the correct helium-to-dpa ratios. This problem has been solved for nickel-bearing materials by using the thermal helium production from ${ }^{59} \mathrm{Ni} .{ }^{13}$ However, this $\mathrm{Ni}$ trick cannot be used for ferritic alloys and fusion simulations are more difficult.

Based on the present work, increased helium-to-displacenent ratios can be readily; achieved in iron or ferritic ailoys irradiated in mixed-spectium resctors by isotopic tailoring. If the observed helium excess is due to thermal neutron production from 
${ }^{55} \mathrm{Fe}$, then iron enriched in ${ }^{54} \mathrm{Fe}$ would increase the helium production from 10 appm to 30-60 appm for a 1 year irradiation in HFIR, depending on the thermal cross section. If we further dope the sample with about $30-60 \%{ }^{55} \mathrm{Fe}$, we would produce about 300 appm helium, thereby achieving a fusion-like 10:1 helium-to-dpa ratio. It is also interesting to note that, with initial ${ }^{55} \mathrm{Fe}$ doping, the helium-to-dpa ratio for iron does nct change very much with neutron fluence and hence is always close to the fusion ratio.

If there is no thermal effect operative, then it would not be possible to achiev. fusion-like helium-to-dpa ratios. Nevertheless, we note that there are large differences in the isotopic cross sections as predicted by THRESH2. Using samples enriched in ${ }^{54} \mathrm{Fe}$ or ${ }^{57} \mathrm{Fe}$ would increase the helium production by factors of 2 to 3 , respectively. Using ${ }^{65} \mathrm{Fe}$ would increase the helium production by a factor of 6 . This would be about a factor of five less than fusion; however, the variation might be enough to predict the influence of helium production on materials property effects.

\section{Discussion and Conclusions}

Our measuremenis demonstrate enhanced helium production in iron irradiated in HFIR. Although we are not presently able to determine precisely the reactions responsible for this enhancement, we note the possibility of a thermal neutron effect from ${ }^{55} \mathrm{Fe}$ which could be used to simulate fusion-like helium-to-dpa ratios in irradiations in mixed-spectrum reactors. Obviously, more measurements are needed to determine the reaction modes and hence the usefulness of this effect. Irradiatione of isotopically enriched iron isotopes would readily determine both fast and thermal neutron cross sections. An irradiation of a sample enriched in ${ }^{65} \mathrm{Fe}$ would rapidly demonstrate the presence of thermal helium production. Data at lower neutron exposures would more accurately determine the required correction to the fast neutron data.

The proposed use of this process to achieve fusion-like helium-to-dpa ratios in iron or ferritic alloys appears to be chemically quite feasible. ${ }^{65} \mathrm{Fe}$ decays by electron capture and only produces low energy $x$-rays and electrons. Consequently, it does not present handling difficulties. The half-life of 2.7 years is long enough to allow fabrication and irradiations up to several years. Although the ${ }^{55} \mathrm{Fe}$ will decay to ${ }^{55} \mathrm{Mn}$, this does not provide a compositional material problem since ${ }^{55} \mathrm{Mn}$ has a high thermal capture cross section to ${ }^{56} \mathrm{Mn}$ which rapidly decays (2.5 hour) to ${ }^{56} \mathrm{Fe}$. Furthermore, $\mathrm{Mn}$ has been suggested as a suitable replacement for $\mathrm{Ni}$ in low-activation alloys for fusion. Finally, ${ }^{55} \mathrm{Fe}$ is available and reasonably cheap, allowing utilization of this technique for fusion materials testing in small specimens. For larger specimens, we note that ${ }^{55} \mathrm{Fe}$ could be produced in quantities from the ${ }^{55} \mathrm{Mn}(\mathrm{p}, \mathrm{n})$ reaction without iron isotopic separations.

\section{Acknowledgements}

This work was supported by the Office of Fusion Energy, U. S. Department of Energy. We would also like to acknowledge the efforts of A. M. Essling and E. G. Rauh of the Analytical Chemistry Laboratory at Aigonne, which also supplied developmental funding of the liquid scintillation counting and mass spectrometry measurements. 


\section{References}

1. D. W. Kneff, L. R. Greenwood, B. M. Oliver, p.nd R. P. Skowronski, J. Nucl. Mater. 141-143,pp.824-828(1986).

2. D. W. Kneff, B. M. Oliver, H. Farrar IV, and L. R. Greenwood, Nucl. Sci. Eng. 92,pp.491-524(1986).

3. D. W. Kneff, B. M. Oliver, M. M. Nakata, and H. Farrar IV, J. Nucl. Mater. 104,pp.1451$55(1981)$.

4. L. R. Greenwood, Damage Analysis and Fundamental Studies Quarterly Frogress Report, DOE/ER-0046/21,pp.9,May 1985.

5. B. M. Oliver, J. G. Bradley, and H. Farrar IV, Geochim. Cosmochim. Acta, 48,1759(1984).

6. Evaluated Neutron Data File (ENDF), Gas Production File 533, Brookhaven National Laboratory (1979).

7. L. R. Greenwood and D. L. Bowers, Meastrement of Long-Lived Isotopes in Fusion Materials, these proceedings.

8. D. L. Bowers and L. R. Greenwood, Analysis of Long-Lived Isotopes by Liquid Scintillation Spectrometry, Proc. Int. Conf. Meih. and Applications of Radioanalytical Chemistry, Kona, Hawaii, April 5-10, 1987, in press.

9. S. F. Mughabghab, M. Divadeenam, and N. E. Holden, Neutron Cross Sections, Vol. I, Academic Press, New York, 1981.

10. E. Browne and R. B. Firestone, Table of Radioactive Isotopes, V. S. Shirley, Ed., John Wiley, New York 1986.

11. A. Anufriev, Proc. Fifth All-Union Conf. on Neutron Physics, 15-19 Sept. 1980, Kiev, USSR.

12. S. Pearlstein, Nucl. Cross Seciions and Technology, Vol. I, NBS Spec. Pub. 425, pp. 332-333(1975).

13. L. R. Greenwood, D. W. Kneff, R. P. Skowronski, and F. M. Mann, J. Nucl. Mater. 123,pp.1002-1010(1984).

14. D. W. Kneff, L. R. Greenwood, B. M. Oliver, H. P. Skowronski, and E. L. Callis, Radiat. Eff. 92-96,pp.553-556(1986).

15. D. W. Kneff, B. M. Oliver, and R. P. Skowronski, Damage Analysis and Fundamental Studies Quarterly Progress Report, DOE/ER-0046/25,pp.12-18,May 1986.

16. B. M. Oliver, D. W. Kneff, and R. P.. Skowronski, ibid, DOE/ER-0046/17,pp.14-16, May 1984. 


\section{Figure Captions}

1. Ratio of calculated-to-experimental helium production for iron samples in RFIR as a function of total neutron fluence. Calculations are compared for ENDF/B-V (no transmutation) and THRESH2 (with calculated isotopic transmutation).

2. Helium cross sections for iron isotopes from THRESH2.

3. Excess helium as derjved from the difference between measurements and fast neutron calculations with either ENDF/B-V or THRESH2. These differences are fit assuming thermal neutron helium production from ${ }^{55} \mathrm{Fe}$ with a cross section of about $18 \mathrm{mb}$ (ENDF) or $9 \mathrm{mb}$ (THRESH). 


\section{Table I}

Helium Measurements and Fast Neutron Calculations for Iron

Fluence Measured ENDF $^{a}$ $\left(10^{26} \mathrm{n} / \mathrm{m}^{2}\right) \quad \mathrm{He}$,appm He,appm

$\begin{array}{rrrrrr}3.48 & 2.24 & 2.38 & 1.06 & 2.48 & 1.11 \\ 4.60 & 2.99 & 3.14 & 1.05 & 3.31 & 1.11 \\ 4.81 & 3.12 & 3.25 & 1.04 & 3.47 & 1.11 \\ 5.57 & 3.66 & 3.68 & 1.01 & 4.04 & 1.10 \\ 8.30 & 5.73 & 5.64 & 0.98 & 6.14 & 1.07 \\ 9.67 & 6.76 & 6.39 & 0.95 & 7.22 & 1.07 \\ 11.05 & 8.17 & 7.64 & 0.94 & 8.33 & 1.02 \\ 16.45 & 12.36 & 10.99 & 0.89 & 12.81 & 1.04 \\ 19.16 & 14.69 & 12.95 & 0.88 & 15.13 & 1.03\end{array}$

${ }^{a}$ Fast helium from ENDF/B-V Gas File $533^{6}$ and natural iron ${ }^{b}$ Calculated-to-experinaental helium ratio 'Fast helium using THRESH2 ${ }^{12}$ and ratios of transmuted iron isotopes 


\section{Table II}

Fe Isotopic Mass Spectrometry Measurements ${ }^{a}$

(Values are atomic percents)

(Calculations based on ENDF/B-V ${ }^{9}$ )

Fluence $\quad{ }^{54} \mathrm{Fe} \quad{ }^{56} \mathrm{Fe} \quad{ }^{57} \mathrm{Fe} \quad{ }^{58} \mathrm{Fe}$

\begin{tabular}{ccccccccc}
$\left(10^{26} \mathrm{n} / \mathrm{m}^{2}\right)$ & Exp. & Calc. & Exp. & Calc. & Exp. & Calc. & Exp. & Calc. \\
\hline 6.37 & 5.02 & 5.01 & 78.36 & 77.70 & 14.84 & 15.00 & 1.28 & 1.68
\end{tabular}

$\begin{array}{lllllllll}3.48 & 5.33 & 5.35 & 83.54 & 83.73 & 10.12 & 9.73 & 0.70 & 0.80\end{array}$

$\begin{array}{lllllllll}3.21 & 5.41 & 5.39 & 84.83 & 84.83 & 8.86 & 9.21 & 0.59 & 0.74\end{array}$

$\operatorname{Mean}(\mathrm{C} / \mathrm{E})$

0.999

0.996

1.003

1.23

${ }^{a}$ Uncertainties: ${ }^{54} \mathrm{Fe} 0.4 \%,{ }^{56} \mathrm{Fe} 0.07 \%,{ }^{57} \mathrm{Fe} 0.3 \%,{ }^{58} \mathrm{Fe} 1.2 \%$ 


\section{Table III}

${ }^{55}$ Fe Measurements and Total Absorption Cross Section (Values are atomic percents at end of irradiation)

Fluence

\begin{tabular}{ccccc}
$\left(10^{26} \mathrm{n} / \mathrm{m}^{2}\right)$ & LIQS $^{a}$ & TIMS $^{b}$ & Calc. $^{c}$ & C/E \\
\hline 6.37 & 0.460 & 0.451 & 0.463 & 1.02 \\
3.48 & 0.317 & 0.323 & 0.309 & 0.97 \\
3.21 & 0.314 & 0.302 & 0.313 & 1.02
\end{tabular}

$$
\text { Mean }=1.00 \pm .03
$$

${ }^{a}$ Liquid scintillation measurements $( \pm 5 \%)$

${ }^{b}$ Thermal ionization mass spectrometry $( \pm 4 \%)$

${ }^{c 55} \mathrm{Fe}$ total absorption cross section $=13.2$ barns;

${ }^{54} \mathrm{Fe}$ capture cross section from ENDF/B-V (Ref. 9)

${ }^{d}$ Ratio of calc./exp. (average of LIQS and TIMS) 
He Ratio (Calc./Exp.)

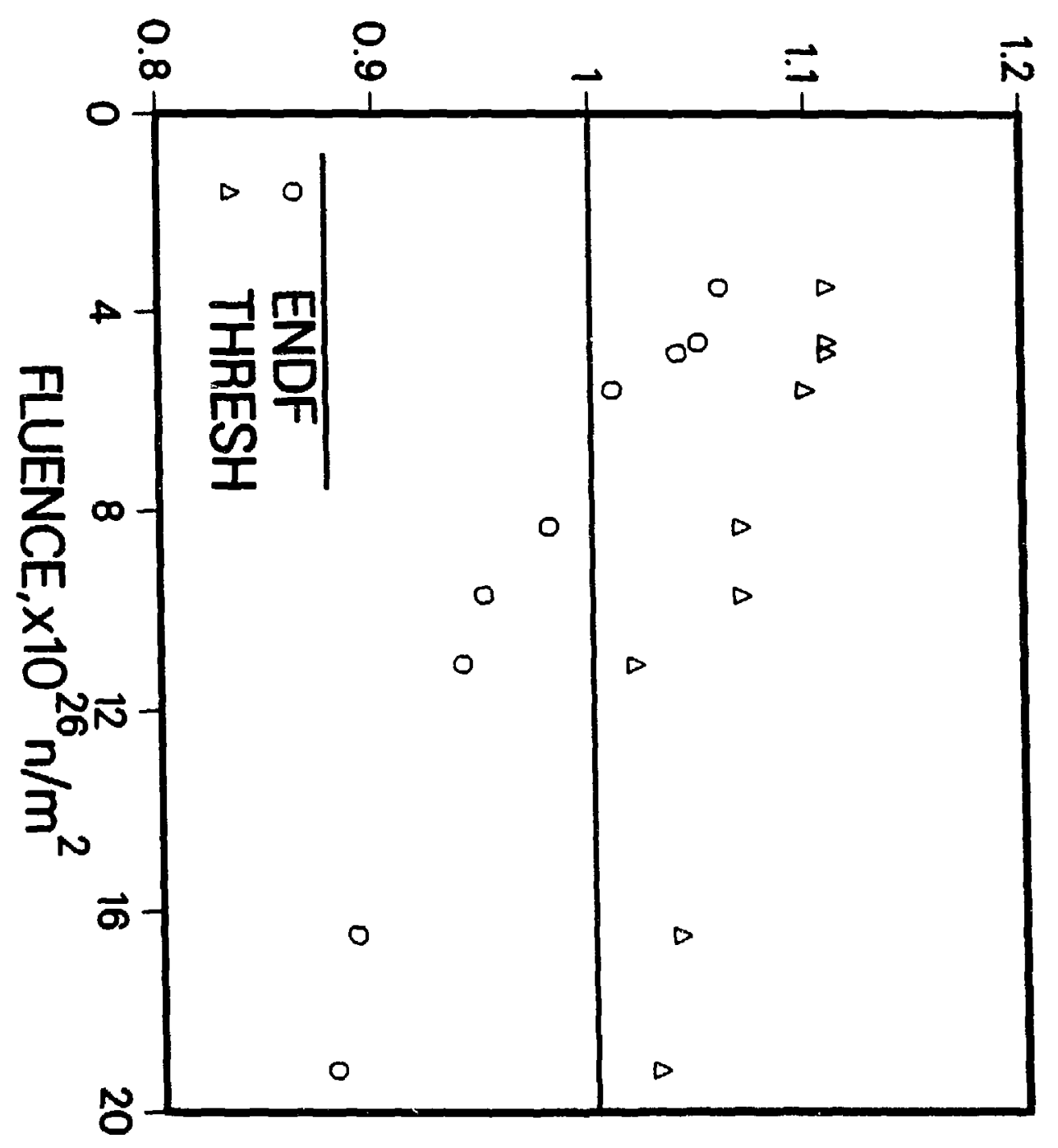




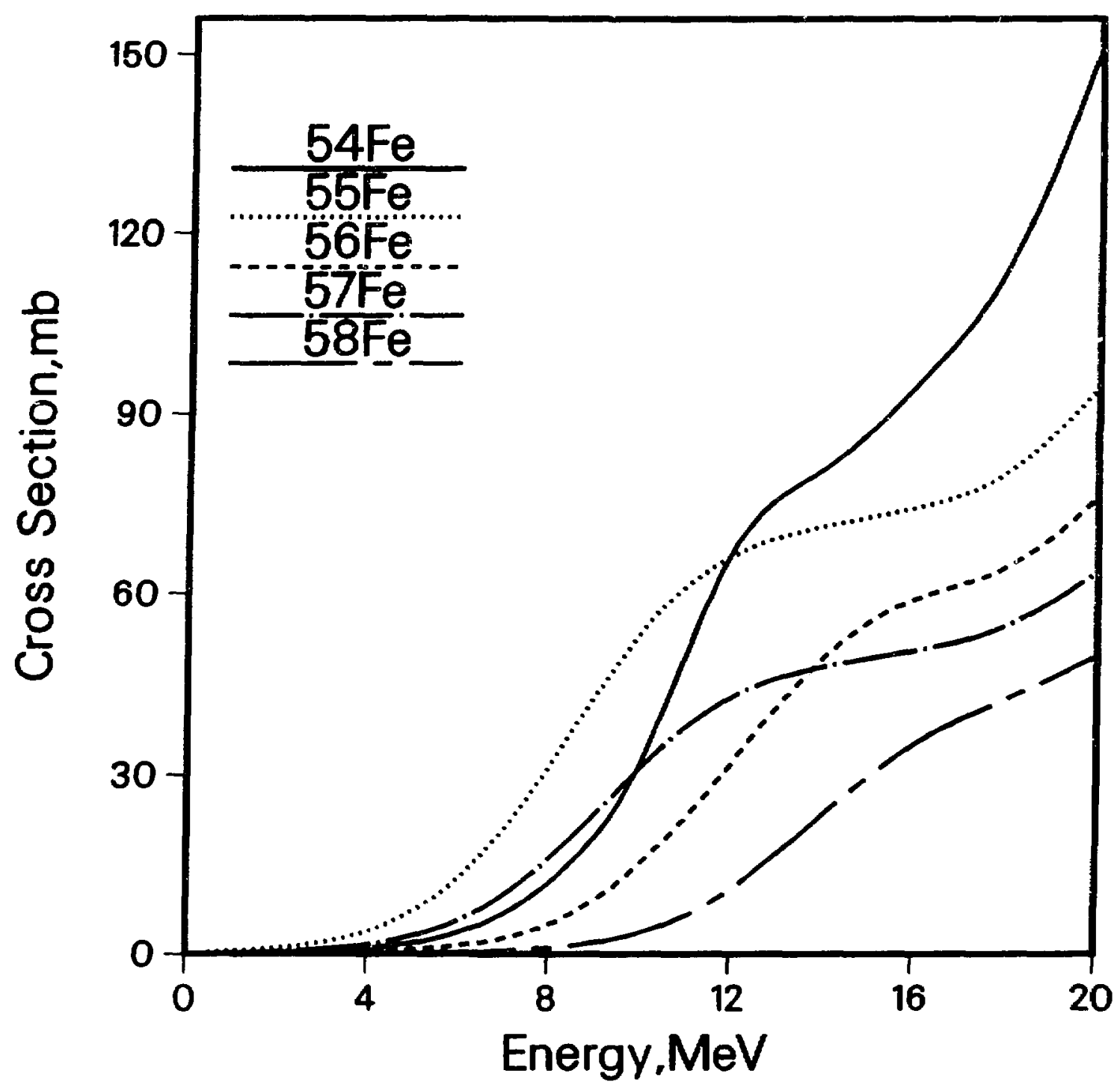




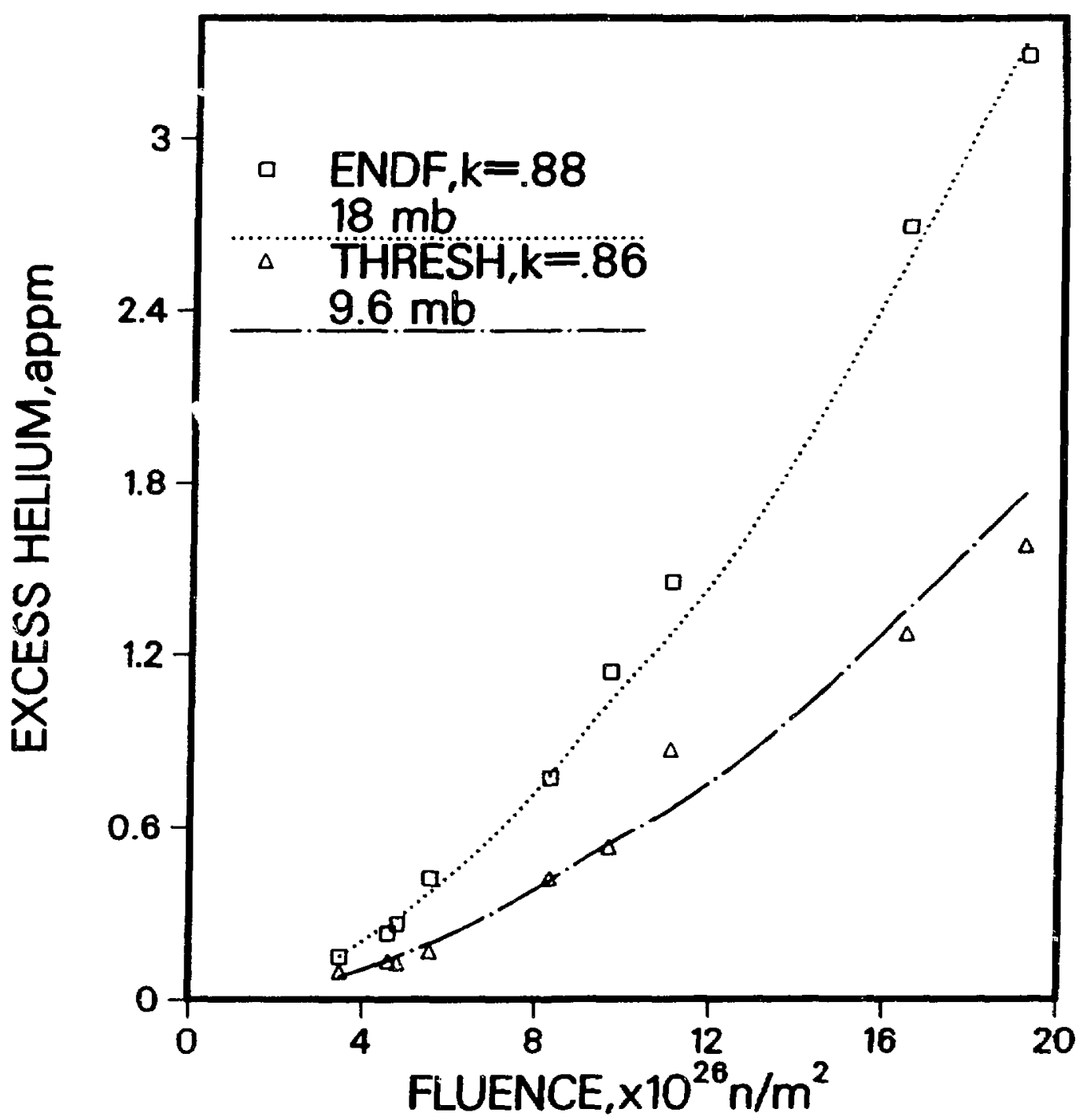

